\title{
Endoscopic Endonasal Approach for a Suprasellar Craniopharyngioma
}

\author{
Georgios A. Zenonos ${ }^{1}$ Carl H. Snyderman ${ }^{2}$ Paul A. Gardner ${ }^{1}$
}

\footnotetext{
${ }^{1}$ Department of Neurosugery, University of Pittsburgh Medical Center, Pittsburgh, Pennsylvania, United States

2 Department of Otolaryngology, University of Pittsburgh Medical Center, Pennsylvania, United States
}

\begin{abstract}
Address for correspondence Paul A. Gardner, MD, Center for Cranial Base Surgery, University of Pittsburgh Medical Center, 200 Lothrop Street, Suite B400, Pittsburgh, PA 15213, United States (e-mail: gardpa@upmc.edu).
\end{abstract}

J Neurol Surg B 2018;79(suppl S3):S241-S242.

\begin{abstract}
Keywords

- craniopharyngioma

- endoscopic endonasal

- suprasellar

- skull base team

Objectives The current video presents the nuances of an endoscopic endonasal approach to a suprasellar craniopharyngioma.

Design The video analyzes the presentation, preoperative workup and imaging, surgical steps and technical nuances of the surgery, the clinical outcome, and follow-up imaging.

Setting The patient was treated by a skull base team consisting of a neurosurgeon and an ENT surgeon, at a teaching academic institution.

Participants The case refers to a 67-year-old man who presented with vision loss and headaches, and was found to have a suprasellar mass, with imaging characteristics consistent with a craniopharyngioma.

Main Outcome Measures The main outcome measures consistent of the reversal of the patient symptoms (vision loss and headaches), the recurrence-free survival based on imaging, as well as the absence of any complications.

Results The patient's vision improved after the surgery; at his last follow-up there was no evidence of recurrence on imaging.

Conclusions The endoscopic endonasal approach is safe and effective in treating suprasellar craniopharyngiomas.

The link to the video can be found at: https://youtu.be/p1VXbwnAWCo.
\end{abstract}

Conflict of Interest

None.

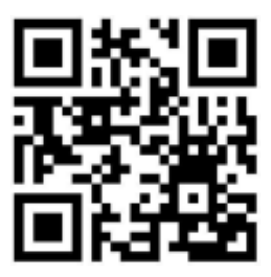

received

October 15, 2017

accepted

December 7, 2017

published online

January 25, 2018 www.thieme.com/skullbasevideos

www.thieme.com/jnlsbvideos
DOI https://doi.org/

10.1055/s-0038-1623522.

ISSN 2193-6331.
๑) 2018 Georg Thieme Verlag KG
Stuttgart · New York

License terms

(c) (i) $\ominus$ (\$) 

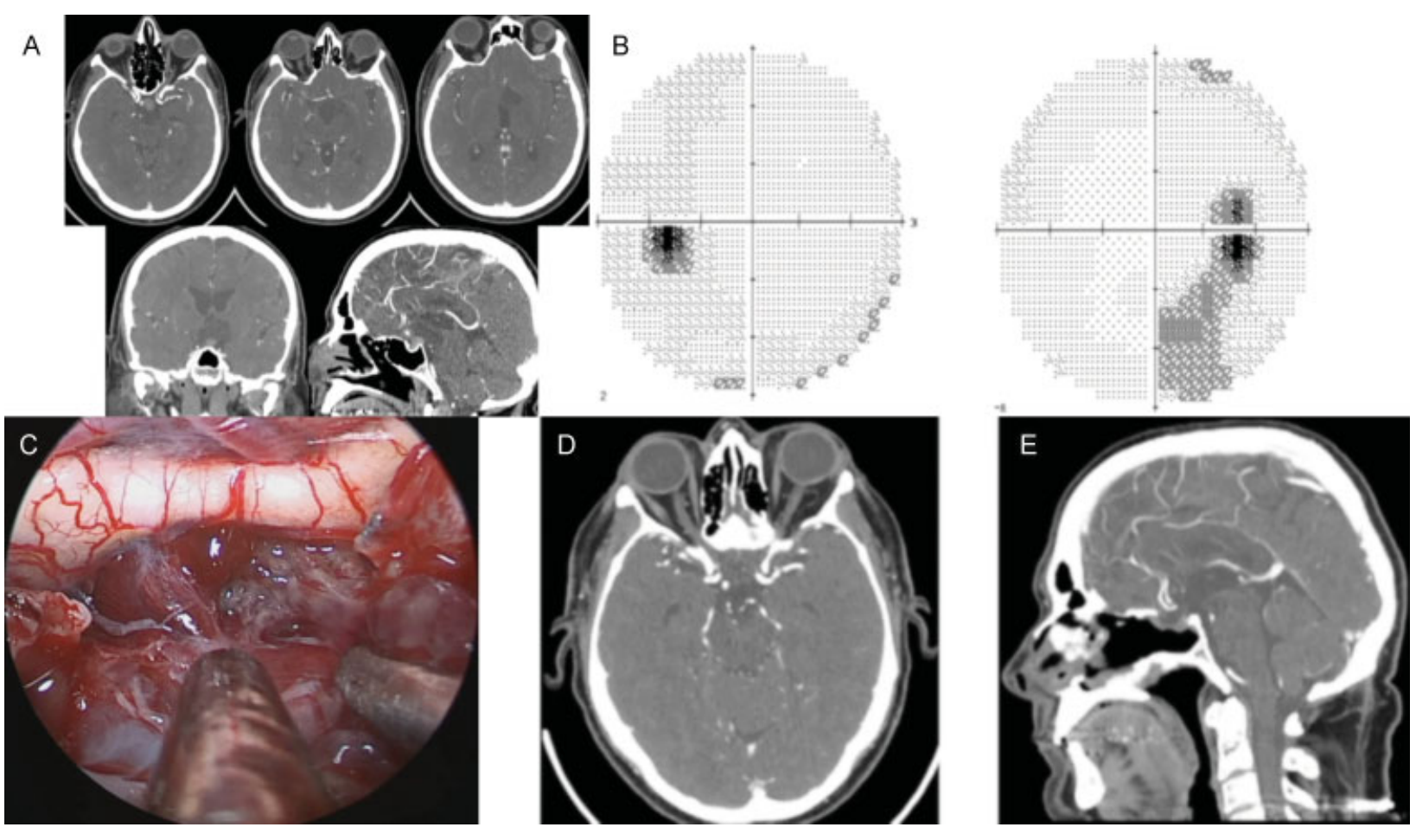

Fig. 1 (A) Preoperative imaging showing a suprasellar cystic lesion consistent with a craniopharyngioma (the patient could not have a magnetic resonance imaging because of shrapnel). (B) Preoperative visual fields showing some right inferior quadrantanopia. (C) Intraoperative image showing the suprasellar exposure and the dissection of the tumor off the pituitary stalk. (D-E) Postoperative imaging at one year of follow-up showing no evidence of recurrence. 